\title{
Anthropometric Indices and Lipid Profiles in Tertiary Institution Students
}

\author{
Mathew Folaranmi Olaniyan ${ }^{1, *}$, Yetunde Ayeni ${ }^{1}$, Folorunso Olabiyi ${ }^{2}$ \\ ${ }^{1}$ Department of Medical Laboratory Science, Achievers University, Owo, Ondo state, Nigeria \\ ${ }^{2}$ Department of Medical Laboratory Science, Afe-Babalola University, Ado-Ekiti-Ekiti State, Nigeria
}

\begin{abstract}
Anthropometric indices and lipid profiles are useful markers of malnutrition and could reveal risk of cardiovascular disease. This work aimed at evaluating the anthropometric indices and lipid profiles in students of tertiary institutions. Anthropometric indices and lipid profiles were evaluated in 200 students of students of tertiary institutions including Achievers University and Rufus Giwa Polytechnic, Owo, Nigeria, aged 18 -46 years, comprising 95 males and 105 females recruited for this study. Anthropometric measurements including weight, height, and waist and hips circumference were measured. Body mass index and waist-hip ratio were also calculated. Fasting lipid profile including total cholesterol (TC), low density lipoprotein cholesterol (LDL), high density lipoprotein cholesterol (HDL), and triglycerides (TG) were estimated biochemically by auto chemistry analyzer. The results showed statistically significant higher mean values of mid arm circumference (MAC) and triglycerides (TG) in the University students than the Polytechnic students studied $(p<0.05)$. A significantly higher mean value of low density lipoprotein (LDL) was obtained in the Polytechnic students than in the University students with $\mathrm{p}<0.05$. The result also showed a significantly higher mean value of MAC, TC, and LDL in females than their male counterparts $(\mathrm{p}<0.05)$. A significantly higher mean value of total triglyceride was, however, obtained in males than in the female students $(\mathrm{p}<0.05)$. This work revealed statistical differences in the MAC, plasma TG, LDL, and TC based on the category of school and gender. We therefore recommend routine measurement of anthropometric indices and blood lipid levels for early detection of malnutrition to avoid complications such as cardiovascular disease.
\end{abstract}

Keywords Anthropometric indices, Lipid, University, Polytechnic, Students

\section{Introduction}

Anthropometry involves the external measurement of morphological traits of human beings. It has a widespread and important place in nutritional assessment, and while the literature on anthropometric measurement and its interpretation is enormous, the extent to which measurement error can influence both measurement and interpretation of nutritional status is little considered [1]. Anthropometric measures are highly reliable for determining the nutritional status when compared with more sophisticated methodologies (hydro-densitometry, dilution techniques and electronic bio-impedance), the use of which is restricted by complexity and cost in population studies [2]. Life styles, nutrition and ethnic composition of populations could cause changes in the distribution of body dimensions (e.g. the obesity epidemic). These changes will require regular updating of anthropometric data collections [3]. Anthropometric values are closely related to nutrition, genetic makeup, environmental characteristics, social and

* Corresponding author:

olaniyanmat@yahoo.com (Mathew Folaranmi Olaniyan)

Published online at http://journal.sapub.org/ajb

Copyright (C) 2014 Scientific \& Academic Publishing. All Rights Reserved cultural conditions, lifestyle, functional status and health. Anthropometric evaluation is an essential feature of geriatric nutritional evaluation for assessment of malnutrition, overweight, obesity, muscular mass loss, fat mass gain and adipose tissue redistribution. Anthropometric indicators are used to evaluate the prognosis of chronic and acute diseases, and to guide medical intervention in the elderly [3]. Changes in body composition differ in men and women at different life stages and are reflected in anthropometric measures. Consequently, different anthropometric indicators are used at different life stages to evaluate the nutritional status [4].

Lipids are a group of naturally occurring molecules that include fats, waxes, sterols, fat-soluble vitamins (such as vitamins $\mathrm{A}, \mathrm{D}, \mathrm{E}$, and $\mathrm{K}$ ), monoglycerides, diglycerides, triglycerides, phospholipids, and others. The main biological functions of lipids include storing energy, signaling, and acting as structural components of cell membranes. Lipids also encompass molecules such as fatty acids, sterol-containing metabolites such as cholesterol. Although humans and other mammals use various biosynthetic pathways to both break down and synthesize lipids, some essential lipids cannot be made this way and must be obtained from the diet. The relationship between cardiovascular disease and lipid profile is well known [5]. This work was therefore designed to determine 
anthropometric indices and lipid profiles in tertiary institution students.

\section{Materials and Method}

\subsection{Materials}

\subsubsection{Subjects}

200 students of tertiary institutions including: Achievers University $(\mathrm{n}=100)$ and Rufus Giwa Polytechnic, $(\mathrm{n}=100)$ both in Owo, Nigeria, aged 18-46 years, comprising 95 males and 105 females, were recruited for this study. Achievers University, Owo, Ondo state-Nigeria is a fee paying private university that runs first degrees in Natural, Laboratory and management sciences with a student population of about 1,000 majorly dominated by students from families of high socio-economic status while Rufus Giwa Polytechnic, Owo-Nigeria is a public (State Government) Polytechnic offering Ordinary and Higher National Diplomas in different fields has a student population of about 5,000 especially those that could not afford the school fees of private schools of equivalent status.

\subsubsection{Collection and Preparation of Samples}

Five milliliters of blood were collected into a lithium heparin bottle. It was centrifuged at $2500 \mathrm{rpm}$ for 5 minutes and the plasma was extracted for biochemical assays.

\subsection{Methods}

\subsubsection{Anthropometric Measurements}

This was carried out at the Nutrition and Dietetics Department of Federal Medical Centre, Owo.

\subsubsection{Weight}

The scale used was balanced and zeroed. The subjects were asked to remove their shoes, and were asked to stand upright in the center without looking down. The weights of the subjects were taken in kilograms.

\subsubsection{Height}

The subjects were instructed to remove their shoes. The subjects were asked to stand with their backs to the height rule. The subjects were asked to look straight ahead, and the measurement in meters was taken by pressing the hair down.

\subsubsection{Waist Circumference}

Waist circumference was measured at a level midway between the lower rib margin and iliac crest with the tape all around the body in a horizontal position, and the waist measurement was taken in centimeters.

\subsubsection{Hip Circumference}

Hip circumference was measured as the maximal circumference over the buttocks, and hip measurement was taken in centimeters.

\subsubsection{Body Mass Index (BMI)}

BMI was estimated by dividing weight $(\mathrm{kg})$ by height ${ }^{2}\left(\mathrm{~m}^{2}\right)$ [6].

$$
\frac{\text { Weight }(\mathrm{kg})}{\operatorname{Height}^{2}\left(\mathrm{~m}^{2}\right)}
$$

\subsubsection{Waist: Hip Ratio (WHR)}

Waist: hip ratio was estimated by dividing waist circumference by hip circumference [7].

\subsection{Biochemical Assays}

Total plasma cholesterol, triglycerides and low density lipoprotein (LDL) were determined [estimated or determined? Estimated would be less accurate] in the subject using Cobas C111 autochemistry analyser using the Cobas reagent kit of Roche. The manufacturer's instructions were strictly followed.

Statistical Analysis: the data was subjected to statistical analysis to determine the mean values, standard deviation and student's' test, for $t$ value, $p$ value and level of significant at 0.05 using online Student T-Test Calculator for 2 Independent Means on line at http://www.socscistatistics. com/tests/studentttest

\subsection{Ethical Approval}

The proposal for this study was reviewed and approved by the Research and Ethical Committee of the Department of Medical Laboratory Science, Achievers University, Owo, Nigeria.

\section{Result}

The result obtained from this work showed a significantly higher mean values of MAC and TG in the university students than the Polytechnic students studied $(p<0.05)$. A significantly higher mean value of LDL was obtained in the Polytechnic students than in the university students with $\mathrm{p}<0.05$ (Table 1).

There was a significantly higher mean value of MAC, TC, and LDL in females than in their male counterparts $(\mathrm{p}<0.05)$. A significantly higher mean value of TG was also obtained in males than in the female students $(p<0.05)$ (Table 2).

Significantly higher mean value of MAC, TC and LDL were obtained in female students of Rufus Giwa Polytechnic than the results obtained in their male counterparts with $\mathrm{p}<$ 0.05 (Table 3 ). There was also a significantly higher mean value of MAC in females of Achievers University, Owo than the mean value obtained in the males with $p<0.05$ (Table 4 ). 
Table 1. Amphoteric and Lipid profile in students of Achivers University (AUO) and Rufus Giwa Polytechnic (RGPO), Owo-Ondo state

\begin{tabular}{cccccc}
\hline PARAMETERS & $\begin{array}{c}\text { AUO } \\
\mathbf{N}=\mathbf{1 0 0}\end{array}$ & $\begin{array}{c}\text { RGPO } \\
\mathbf{n = 1 0 0}\end{array}$ & T-value & P-value & REMARKS \\
\hline BMI & $21.46 \pm 2.23$ & $22.54 \pm 2.70$ & -1.555 & $\mathrm{P}>0.05$ & Not-significant \\
W/H RATIO & $0.89 \pm 0.07$ & $0.88 \pm 0.06$ & 0.604 & $\mathrm{P}>0.05$ & Not-significant \\
MAC & $10.48 \pm 0.72$ & $9.72 \pm 1.14$ & 2.551 & $\mathrm{P}<0.05$ & Significant \\
TC & $2.98 \pm 0.97$ & $3.08 \pm 0.72$ & -489 & $\mathrm{P}>0.05$ & Not-significant \\
TG & $1.34 \pm 0.50$ & $1.04 \pm 0.34$ & 2.869 & $\mathrm{P}<0.05$ & Significant \\
HDL & $0.66 \pm 0.23$ & $0.65 \pm 0.12$ & 0.84 & $\mathrm{P}>0.05$ & Not-significant \\
LDL & $1.45 \pm 0.79$ & $2.01 \pm 0.69$ & -2.690 & $\mathrm{P}<0.05$ & Significant \\
\hline
\end{tabular}

Table 2. Amphoteric and Lipid profiles in female and male students of Achievers University and Rufus Giwa Polytechnic, Owo-Ondo state

\begin{tabular}{cccccc}
\hline PARAMETERS & $\begin{array}{c}\text { Females } \\
\mathbf{N}=\mathbf{1 0 5}\end{array}$ & $\begin{array}{c}\text { Males } \\
\mathbf{N}=\mathbf{9 5}\end{array}$ & T-value & P-value & REMARKS \\
\hline BMI & $23.9 \pm 3.76$ & $22.29 \pm 2.43$ & 1.142 & $\mathrm{P}>0.05$ & Not-significant \\
W/H RATIO & $0.86 \pm 0.05$ & $0.88 \pm 0.06$ & -1.171 & $\mathrm{P}>0.05$ & Not-significant \\
MAC & $10.55 \pm 1.39$ & $9.67 \pm 0.89$ & 2.658 & $\mathrm{P}<0.05$ & Significant \\
TC & $3.56 \pm 0.79$ & $2.96 \pm 0.71$ & 3.571 & $\mathrm{P}<0.05$ & Significant \\
TG & $0.68 \pm 0.23$ & $0.89 \pm 0.37$ & -2.356 & $\mathrm{P}<0.05$ & Significant \\
HDL & $0.46 \pm 0.15$ & $0.47 \pm 0.14$ & -212 & $\mathrm{P}>0.05$ & Not-significant \\
LDL & $2.79 \pm 0.75$ & $2.09 \pm 0.68$ & 4.262 & $\mathrm{P}<0.05$ & Significant \\
\hline
\end{tabular}

Table 3. Amphoteric and Lipid profiles in female and male students of Achievers University Owo-Ondo state

\begin{tabular}{cccccc}
\hline PARAMETERS & $\begin{array}{c}\text { Females } \\
\mathbf{N}=\mathbf{1 0 5}\end{array}$ & $\begin{array}{c}\text { Males } \\
\mathbf{N}=\mathbf{9 5}\end{array}$ & T-value & P-value & REMARKS \\
\hline BMI & $25.0 \pm 3.5$ & $23.1 \pm 2.5$ & 0.5547 & $\mathrm{P}>0.05$ & Not-significant \\
W/H RATIO & $0.83 \pm 0.03$ & $0.87 \pm 0.05$ & 1.2 & $\mathrm{P}>0.05$ & Not-significant \\
MAC & $10.7 \pm 0.15$ & $9.5 \pm 0.08$ & 7.0 & $\mathrm{P}<0.05$ & Significant \\
TC & $3.7 \pm 0.6$ & $3.0 \pm 0.5$ & 2.4 & $\mathrm{P}>0.05$ & Not Significant \\
TG & $0.7 \pm 0.2$ & $0.9 \pm 0.3$ & 0.6 & $\mathrm{P}>0.05$ & Not Significant \\
HDL & $0.51 \pm 0.1$ & $0.47 \pm 0.14$ & 0.3 & $\mathrm{P}>0.05$ & Not-significant \\
LDL & $3.1 \pm 0.8$ & $2.2 \pm 0.8$ & 1.1 & $\mathrm{P}>0.05$ & Not Significant \\
\hline
\end{tabular}

Table 4. Amphoteric and Lipid profiles in female and male students of Rufus Giwa Polytechnic, Owo-Ondo state

\begin{tabular}{cccccc}
\hline PARAMETERS & $\begin{array}{c}\text { Females } \\
\mathbf{N}=\mathbf{1 0 5}\end{array}$ & $\begin{array}{c}\text { Males } \\
\mathbf{N}=\mathbf{9 5}\end{array}$ & T-value & P-value & REMARKS \\
\hline BMI & $23.9 \pm 3.76$ & $22.29 \pm 2.43$ & 1.7 & $\mathrm{P}>0.05$ & Not-significant \\
W/H RATIO & $0.9 \pm 0.05$ & $0.9 \pm 0.06$ & 1.2 & $\mathrm{P}>0.05$ & Not-significant \\
MAC & $10.45 \pm 1.5$ & $9.8 \pm 0.75$ & 2.7 & $\mathrm{P}<0.05$ & Significant \\
TC & $3.7 \pm 0.1$ & $2.7 \pm 0.1$ & 3.1 & $\mathrm{P}<0.05$ & Significant \\
TG & $0.7 \pm 0.2$ & $0.9 \pm 0.3$ & 0.6 & $\mathrm{P}>0.05$ & Not Significant \\
HDL & $0.6 \pm 0.3$ & $0.5 \pm 0.2$ & 0.3 & $\mathrm{P}>0.05$ & Not-significant \\
LDL & $3.9 \pm 0.3$ & $2.0 \pm 0.1$ & 6.0 & $\mathrm{P}<0.05$ & Significant \\
\hline
\end{tabular}

\section{Discussion}

This work was used to evaluate anthropometric indices and lipid profiles in tertiary institution students using students of Achievers University and Rufus Giwa Polytechnic, both in Owo Ondo state in Nigeria, as samples for nutritional assessment and evaluation of cardiovascular risk.

Significantly higher mean values of MAC and TG in the university students than the Polytechnic students could be attributed to the fact that Life styles, nutrition and ethnic composition of populations could cause changes in the distribution of body dimensions (e.g. the obesity epidemic)
[3]. This could also be related to the previous findings that University students had frequent snacking habits [11] and had a higher frequency of fast food consumption .Most Fasts food is delicious but it is supposed to be dangerous to health and may cause clogget heart, hypertension. Fast food includes those food items, which can are prepared and serve quickly. Nutritional analysis shows that generally fast foods are high in fat value specially saturated fat, energy density, fructose and glycemic index, but poor in fiber, vitamins A and $\mathrm{C}$ and calcium [12]. Furthermore anthropometric and lipid values are closely related to nutrition, genetic makeup, environmental characteristics, social and cultural conditions, lifestyle, functional status and health. Anthropometric 
evaluation is an essential feature of geriatric nutritional evaluation for assessment of malnutrition, overweight, obesity, muscular mass loss, fat mass gain and adipose tissue redistribution. [3]. A significantly higher mean value of LDL was also found in the Polytechnic students than the University students with $\mathrm{p}<0.05$. The differences in the plasma lipids among students of tertiary institution was also reported by Brevard and Ricketts [9] when dietary intake, physical activity, and serum lipid levels of college students living on and off campus were compared. This could also be attributed to the reports of previous studies that behavioral consequences of stress may affect eating habits which may also affect the level of biochemical parameters such as lipids $[13,14]$. Differences in plasma lipids among the students could be associated with the report of Karamehic et al [10] that studied students of the University of Sarajevo and found that Total serum cholesterol was minimally elevated in 7,1\% of tested students, elevated with high risk in $2,7 \%$ and triglycerides were minimally elevated in 1,8\%. Presence of elevated LDL cholesterol was found to be $2,7 \%$ minimally and $1,8 \%$ with high risk. HDL cholesterol was minimally decreased in 1 tested student.

The significantly higher mean value of MAC, TC, LDL in females than in their male counterparts and a significantly higher mean value of TG in males than in the female students. Significantly higher mean values of MAC, TC and LDL were obtained in female students of Rufus Giwa Polytechnic than the results obtained in their male counterparts and also a significantly higher mean value of MAC in females of Achievers University, Owo than the mean value obtained in the males. These findings are consistent with the fact that changes in body composition differ in men and women at different life stages and are reflected in anthropometric and biochemical measures [4].

Related fact to these findings include the following; that in European men and women, fat distribution may be responsible for male/female differences in serum triglycerides but that such conclusions are less clear for HDL-, total- and LDL-cholesterol [15] and that subcutaneous fat deposition in female infants has been found to be significantly increased [16]. The result of this study could also be attributed to differences in the lifestyle including food intake in both sexes [8] and that biochemical (lipids) and anthropometric values are closely related to nutrition, genetic makeup, environmental characteristics, social and cultural conditions, lifestyle, functional status, differences in academic stress affecting eating habits, and health. [3, 13, 14]. Also Poor eating habits is a major public health concern among young adults who experienced transition into university life [17], during which, they are exposed to stress and lack of time which could lead total dependence on fast foods rich in fat $[18,19,20]$. These factors pose a barrier against adoption of healthy behaviors, such as poor eating habits and substance abuse [17]. Although these behaviors of students are considered temporary, as part of university life; unhealthy habits picked up at this age generally persist in older adult life [19] The findings of this work could also be associated with the differences of socioeconomic status (which may affect the eating habit and consequently the nutritional status) between the two school because Achievers University, Owo, Ondo state- Nigeria is a fee paying private university that runs first degrees in Natural, Laboratory and management sciences with a student population of about 1,000 dominated by students from families of high socio-economic status while Rufus Giwa Polytechnic, Owo-Nigeria is a resident public (State Government owned) Polytechnic offering Ordinary and Higher National Diplomas in different fields has a student population of about 5,000 especially those that could not afford the school fees of private schools of equivalent status. The Students of the university are fully accommodated in the campus while majority of the Polytechnic students including the study sample live off-campus $[3,13,17]$.

\section{Conclusions}

This work has been used to measure anthropometric indices (weight, height, and waist and hips circumference), and lipid profiles in tertiary institution students the result obtained therefore revealed:

1. A significantly higher mean values of MAC and TG in the university students than in the Polytechnic students.

2. A significantly higher mean value of LDL was obtained in the Polytechnic students than in the university students.

3. A significantly higher mean value of MAC, TC, and LDL was found in females than in their male counterparts

4. A significantly higher mean value of TG in male than in the female students.

5. Significantly higher mean values of MAC, TC and LDL in female students of Rufus Giwa Polytechnic than the results obtained in their male counterparts and there was also a significantly higher mean value of MAC in females of Achievers University, Owo than the mean value obtained in the males

\section{Recommendations}

Routine analyses of the anthropometric indices and lipids are hereby suggested for nutritional counseling and early detection of cardiovascular risk.

\section{REFERENCES}

[1] Ulijaszek S.J, Kerr DA. Anthropometric measurement error and the assessment of nutritional status.Br J Nutr 2000 Jan; 83(1):95.

[2] Kyle U.G, Genton L and Pichard C., Body Composition: What's New? Curr. Opin. Clin. Nutr. Metab. Care 2002: $5: 427-433$. 
[3] Villareal DT, Apovian CM, Kushner RF and Klein S., The Obesity Society: Obesity in Older Adults: Technical Review and Position Statement of the American Society for Nutrition and NAASO, The Obesity Society. Am. J. Clin. Nutr: 2005: 82:923-934.

[4] Perissinotto E, Pisent C, Sergi G, Grigoletto F. and ILSA Working Group (Italian Longitudinal Study on Ageing), Anthropometric Measurements in the Elderly: Age and Gender Differences. Br. J Nutr. 2002: 87:177-186.

[5] Juan M.A, Pilar S. C, Aritz .U, José M. M and Jesús S. Changes induced by diet and nutritional intake in the lipid profile of female professional volleyball players after 11 weeks of training. Journal of the International Society of Sports Nutrition 2013 10:55.

[6] Gallagher D.W. How useful is BMI for comparison of body fatness across age, sex and ethnic group, American journals of epiderminology 1996:143, 228-239.

[7] WHO. Physical Status, The use and interpreatation of Antropometry Geneve, Switzerland: World health Organisation 1995: technical report.

[8] Bog-Hieu. L. .Nutritional status, blood lipid profiles, and life style in Korean vegetarians and omnivores. The FASEB Journal. 2007;21:693.3.

[9] Brevard P.B.1, Ricketts C.D.Residence of college students affects dietary intake, physical activity, and serum lipid levels. J Am Diet Assoc. 1996 Jan;96(1):35-8.

[10] Jasenko K, Jozo C, Tomislav J, Mirsad P, Oggi R, Goran R. Serum lipids and lipoproteins among students of the University of Sarajevo. Medical Archives 01/2011; 65(4):199-201.

[11] Yahia N, Achkar A, Abdallah A, Rizk S: Eating habits and obesity among Lebanese university students Nutr J 2008, 7(32):. http://www.nutritionj.com/content/7/1/3212.
[12] Alizadeh M, Ghabili K: Health related lifestyle among the Iranian medical students. Res Biol Sci 2008, 3(1):4-9.

[13] Torres S, Nowson C: Relationship between stress, eating behavior and obesity. Nutrition 2007, 23(11-12):887-894. PubMed Abstract | Publisher Full Text OpenURL.

[14] Adam T, Epel E: Stress, eating and the reward system.Physiol Behav 2007, 91:449-458. PubMed Abstract | Publisher Full Text OpenURL.

[15] Seidell JC, Cigolini M, Charzewska J, Ellsinger BM, Björntorp P, Hautvast JG, Szostak W.Fat distribution and gender differences in serum lipids in men and women from four European communities. Atherosclerosis. 1991 Apr; 87(2-3):203-10.

[16] Copper RL1, Goldenberg RL, Cliver SP, DuBard MB, Hoffman HJ, Davis RO Anthropometric assessment of body size differences of full-term male and female infants. Obstet Gynecol. 1993 Feb;81(2):161-4.

[17] Nelson MC, Story M, Larson NI, Neumark-Sztainer D, Lytle LA: Emerging adulthood and college-aged youth: An overlooked age for weight-related behavior cha Obes 2008, 16(10):2205-2211.

[18] Rubina A, Shoukat S, Raza R, Shiekh MM, Rashid Q, Siddique MS, Panju S, Raza H, Chaudhry S, Kadir M: Knowledge and practice of healthy lifestyle and dietary habits in medical and non-medical students of Karachi, Pakistan. J Pak Med Assoc 2009, 59(9):650-655.

[19] Webb E, Ashton CH, Kelly P, Kamah F: An update on British medical students' lifestyles. Med Educ 1998, 32:325-331.

[20] Man M. P, Santosh. G, Rajendra, C Fast food (French fries) induced changes in lipid profile. Int J Biol Med Res. 2010; 1(3): $82-84$. 